\title{
Lung volume reduction surgery (LVRS) for chronic obstructive pulmonary disease (COPD) with underlying severe emphysema
}

\author{
Jackie Young, Anne Fry-Smith, Chris Hyde
}

\begin{abstract}
Background-Lung volume reduction surgery (LVRS) has recently re-emerged as a surgical option for the treatment of end stage chronic obstructive pulmonary disease (COPD) due to underlying severe emphysema. Advocates of LVRS claim that it represents a significant breakthrough in the management of this challenging group of patients while sceptics point to uncertainty about the effectiveness of the operation.
\end{abstract}

Methods-A systematic review was conducted of the evidence on the effects of LVRS in patients with end stage COPD secondary to severe emphysema.

Results-The most rigorous evidence on the effectiveness of LVRS came from case series. Seventy five potentially relevant studies were identified and 19 individual series met the methodological criteria for inclusion. The pattern of results was consistent across individual studies despite a significant degree of clinical heterogeneity. Significant short term benefits occurred across a range of outcomes which appeared to continue into the longer term. Physiological improvements were matched by functional and subjective improvements. Early mortality rates were low and late mortality rates compared favourably with those of the general COPD population. However, the entire research base for the intervention is subject to the limitations of study designs without parallel control groups.

Conclusions-LVRS appears to represent a promising option in the management of patients with severe end stage emphysema. However, until the results of ongoing clinical trials are available, the considerable uncertainty that exists around the effectiveness and cost effectiveness of the procedure will remain.

(Thorax 1999;54:779-789)

Keywords: lung volume reduction surgery; chronic obstructive pulmonary disease; emphysema

Lung volume reduction surgery (LVRS) has recently emerged as a new surgical procedure for the treatment of end stage chronic obstructive pulmonary disease (COPD) due to underlying severe emphysema. COPD is an important cause of mortality and morbidity in the UK which has one of the highest rates in Europe. ${ }^{1}$ In 1995 the age standardised annual death rates were 50 per 100000 in men and 24 per 100000 in women. ${ }^{2}$ Mortality and morbidity rates rise steeply with age with most deaths occurring in elderly subjects, but with about $4 \%$ of premature deaths in the 55-65 age group attributable to COPD. ${ }^{3}$ Patients with COPD form a major part of the workload in both primary and secondary care, typically accounting for around 680 hospital admissions, 9600 inpatient days, and 14200 general practice consultations a year in an average health district of 250000 people. ${ }^{4}$

Very few treatment options are available for patients with end stage COPD and their management represents a considerable challenge for respiratory physicians. Most of the treatments currently available are directed generally at COPD and aim simply to improve the patient's experience of health and well being rather than to cure the condition, and many have associated adverse side effects. A typical package of care for a patient who might be eligible for LVRS would include maximum medical therapy with inhaled or nebulised bronchodilators and steroids, supplemental oxygen, pulmonary rehabilitation, smoking cessation advice and support, early treatment of infection and management of acute exacerbations, management of anxiety and depression, and home care and social support.

LVRS involves the resection of the most functionless areas of lung in cases of diffuse emphysema and should be differentiated from procedures such as bullectomy which involve the excision of areas of lung because they are diseased. The procedure was first introduced by Dr Otto Brantigan at the University of Maryland in the $1950 \mathrm{~s}^{56}$ and has recently been revisited by Dr Joel Cooper in St Louis who has achieved improved mortality and morbidity rates by using modern surgical developments to modify the original technique. ${ }^{78} \mathrm{~A}$ range of techniques and surgical approaches are currently available for LVRS. It can be performed as an open or closed procedure, unilaterally or bilaterally, and lung tissue can be excised using stapling, laser plication, or both. Current consensus is that the best technique is bilateral stapling via a median sternotomy, with suture line reinforcement using bovine pericardium strips. ${ }^{9}$

Advocates of LVRS claim that it represents a significant breakthrough in the management of this challenging group of patients. In the USA, despite increasing enthusiasm for the procedure among patients and surgeons, Medicare have refused to fund any further operations on 
Table 1 Inclusion and exclusion criteria

\begin{tabular}{|c|c|c|}
\hline & Inclusion & Exclusion \\
\hline Population & $\begin{array}{l}\text { Patients with diffuse severe emphysema with significant } \\
\text { functional limitation despite maximum medical therapy }\end{array}$ & $\begin{array}{l}\text { Patients with large isolated emphysematous bullae in the } \\
\text { presence of normal underlying compressed lung }\end{array}$ \\
\hline Intervention & $\begin{array}{l}\text { Lung volume reduction surgery (reduction pneumoplasty or } \\
\text { pneumectomy) defined as multiple lung resections and/or } \\
\text { plications of diseased lung tissue to reduce lung volume. The } \\
\text { following techniques and approaches were all included: open or } \\
\text { closed procedure, unilateral or bilateral procedure, laser } \\
\text { ablation, stapling or both }\end{array}$ & The excision of localised giant bullae \\
\hline Outcomes & $\begin{array}{l}\text { Studies were included irrespective of which outcomes they } \\
\text { addressed. Ideally, they would address clinical and } \\
\text { physiological outcomes and should provide data on morbidity } \\
\text { and mortality rates associated with the procedure }\end{array}$ & $\begin{array}{l}\text { Studies which only considered short term outcomes, i.e. those } \\
\text { with less than three months follow up } \\
\text { Studies which primarily examined the mechanism of effect of } \\
\text { LVRS as opposed to the effectiveness of the intervention in } \\
\text { improving patients' symptoms, leading to the measurement of } \\
\text { inappropriate and non-clinically important outcomes }\end{array}$ \\
\hline Duplication & $\begin{array}{l}\text { When several series emerged chronologically from the same } \\
\text { source only the largest and most recent series was included }\end{array}$ & $\begin{array}{l}\text { Studies were excluded if they had clearly originated from the } \\
\text { same source and there were indications that their analysis } \\
\text { included some or all of the same patients }\end{array}$ \\
\hline \multicolumn{3}{|c|}{ Quality criteria (pertaining to potential sources of bias) } \\
\hline Selection bias & $\begin{array}{l}\text { A consecutive case series: cases studied represented all those } \\
\text { treated or were shown to have been selected in an unbiased } \\
\text { way or were shown not to be significantly different from the } \\
\text { total number treated }\end{array}$ & $\begin{array}{l}\text { A selected case series: cases studied were a subgroup of those } \\
\text { treated with no detail provided as to how they were selected or } \\
\text { cases studied were a subgroup of those treated with no } \\
\text { evidence to show that they were not significantly different from } \\
\text { the total number treated }\end{array}$ \\
\hline Attrition bias & $\begin{array}{l}\text { Losses to follow up of } \leqslant 25 \% \text { or adequate management of } \\
\text { losses to follow up, e.g. demonstration that they were not } \\
\text { significantly different from total population; inclusion in the } \\
\text { final analysis; or sensitivity analyses. NB. When losses to follow } \\
\text { up arose due to cases in the series not reaching a given follow } \\
\text { up point, studies were included if they treated cases on whom } \\
\text { data were available as a cohort with results presented for that } \\
\text { discrete cohort before and after the intervention }\end{array}$ & $\begin{array}{l}\text { Losses to follow up }>25 \% \text { and inadequate management of } \\
\text { losses to follow up }\end{array}$ \\
\hline Detection bias & $\begin{array}{l}\text { Prospective study design: study states that it was conducted } \\
\text { prospectively or outcomes of interest were clearly measured } \\
\text { before and after the intervention using predefined criteria }\end{array}$ & $\begin{array}{l}\text { Retrospective study design: study states that it was conducted } \\
\text { retrospectively or outcomes of interest were clearly not } \\
\text { measured before and after the intervention using predefined } \\
\text { criteria }\end{array}$ \\
\hline
\end{tabular}

the grounds that a robust research base on the effectiveness of the intervention does not exist. ${ }^{10}$ At the moment the procedure is not routinely funded by health authorities in the UK. Although considerable uncertainty exists about the overall balance of benefits and risks, there is a growing interest in and demand for the procedure from both clinicians and, increasingly, from patients themselves.

Existing reviews on the topic do exist ${ }^{911-22}$ but the majority are not systematic, up to date, or comprehensive in their coverage of the literature. The aim of this review is to review systematically the evidence on the effects of LVRS in patients with end stage COPD due to underlying emphysema.

\section{Methods}

SEARCH STRATEGY

A broad comprehensive search strategy was developed which was designed to identify any potentially relevant material on LVRS for COPD. The key elements of this strategy were as follows: electronic searches of MEDLINE and EMBASE using terms such as "surgery", "emphysema", "pneumectomy", and "pneumoplasty"; searches of the Cochrane Library Controlled Clinical Trials Register; contacts with experts in the field to identify ongoing or unpublished research; and citation checking of all articles obtained. Full details of the search strategy are available on request from the authors. All sources were searched from 1975 onwards and no language exclusion or other limits were applied, particularly in relation to study design.
INCLUSION AND EXCLUSION DECISIONS AND QUALITY ASSESSMENT

All inclusion and exclusion decisions were made independently of the detailed scrutiny of the results of the studies, cross checked by two reviewers (JY and $\mathrm{CH}$ ), and made using predetermined criteria which incorporated detail pertaining to the methodological quality of the anticipated studies. The final criteria used are contained in table 1 .

Initially, the abstracts of all identified articles were scanned for relevance by one reviewer (JY). When abstracts were not available the full article was obtained. The inclusion and exclusion criteria were applied by one reviewer (JY) and cross checked by the other $(\mathrm{CH})$. Any discrepancies were resolved by discussion.

Additional detail on methodological quality was recorded and tabulated for each of the included studies.

DATA ABSTRACTION AND ANALYSIS

The characteristics and results of the included studies were abstracted by one reviewer (JY) using a proforma. RevMan 3.1 for Windows software was used to record this information and to generate summary tables. The tabulated data were qualitatively assessed, particularly in relation to possible sources of heterogeneity. The general design, quality and clinical heterogeneity of the included studies made a formal meta-analysis inappropriate but the tabulation process enabled the identification of a range of plausible values for the likely effect of LVRS on the key outcomes of interest. When necessary the results of the individual studies were re-analysed, involving the re-calculation of certain data to facilitate comparison-for example, the conversion of all six minute walk- 
ing distances to metres and the calculation of pre/post test differences when these were not reported by the study authors. Data were summarised using additional statistics such as interquartile range to give an indication of the general size and direction of effect. The potential for publication bias was also investigated.

\section{Results}

VOLUME OF RELEVANT MATERIAL

Initially, 198 references were identified by the formal search; 123 were excluded on the basis of the information contained in the title or the abstract and 75 full text papers were obtained, either because a decision could not be made using the available information or because they were potentially relevant for inclusion. Nineteen studies met the criteria for inclusion in the final analysis. The main reasons for exclusion were: suspicion of duplication; measurement of inappropriate or irrelevant outcomes; the evaluation of interventions other than LVRS as defined in this review; and inadequate methodological quality. Details of all excluded studies are available on request from the authors. All 19 included studies were case series but a small number of trials were also identified. All of the trials examined the effectiveness of different techniques for LVRS and not the effectiveness of the intervention as a whole and as such were not suitable for inclusion. However, where possible the individual comparison groups from these trials were included as case series in their own right.

CHARACTERISTICS OF INCLUDED STUDIES

The characteristics of the studies included in this review are shown in table 2. The key features are described below.

\section{Intervention}

Although the majority of the results reflect those of the currently preferred technique, in some studies a different operative technique or approach was used. In particular, in a number of the earlier studies laser was used to obliterate the areas of diseased lung and in a few of the more recent studies the procedure was conducted by video assisted thoracoscopy.

Rehabilitation has been shown to have an effect on exercise capacity and quality of life in patients with COPD so the estimate of effect may well be influenced by this. ${ }^{23}$ The reporting of participation in pulmonary rehabilitation was inconsistent and, when it was reported, the timing of baseline data collection in relation to preoperative rehabilitation was not clear leading to considerable ambiguity overall about whether or not the effect of LVRS and pulmonary rehabilitation was being evaluated.

One additional factor which may have had a bearing on the results, for what is essentially an experimental technique, is the level of skill and experience of the operators. An estimate of this was obtained from information on the setting of the study and the duration of the programme. Generally, the studies took place in the context of large programmes in university hospitals or specialist medical centres, al- though on the few occasions when this was not the case the pattern of results was fairly consistent.

\section{Populations examined}

The populations examined also varied between the individual studies in terms of their selection criteria. Generally these exhibited a high degree of selectivity. However, this is likely to be the way LVRS is going to continue to be applied in the immediate future.

\section{Outcomes}

There was more consistency between the studies in the range of outcomes that were measured. Most collected objective outcome data on both the physiological and functional aspects of the procedure using standardised assessment tools, and mortality and morbidity data were generally provided. Dyspnoea was assessed by several studies but quality of life measures were used on only a few occasions. For all of the more subjective outcomes there was considerable variation in the measurement tools used.

\section{Study design}

All of the final group of included studies were case series. Because they were selected partly on the basis of the validity assessment, there was a high degree of consistency between them in relation to their methodological quality. Most were consecutive case series of a good size which were conducted prospectively with minimal losses to follow up.

However, because they were all observational studies which did not use parallel control groups, an element of uncertainty exists about the reliability and accuracy of the reported results. The reasons for this uncertainty are explored more fully in the discussion section of this paper.

In addition to this general point, none of the studies stated that the assessment of outcomes was undertaken by independent observers, raising the specific potential for the influence of detection bias on the results.

\section{RESULTS OF INCLUDED STUDIES}

Mortality

Early and late mortality rates could be calculated for most series and these data are presented in detail for 567 patients in table 3 . The interquartile range (IQR) for early mortality (defined as hospital deaths or deaths occurring within 30 days of surgery) was $0-6 \%$, while the IQR for late mortality (defined as deaths occurring in the hospital or more than 30 days after surgery) at 3-6 months was $0-8 \%$. Late mortality at two years was estimated as between $0 \%$ and $3 \%$.

\section{Lung function}

Most studies collected data on a range of physiological outcomes including the forced expiratory volume in one second $\left(\mathrm{FEV}_{1}\right)$. The results of the individual studies for $\mathrm{FEV}_{1}$ and $\mathrm{FEV}_{1}$ as a percentage of the predicted value are presented in table 4 . 


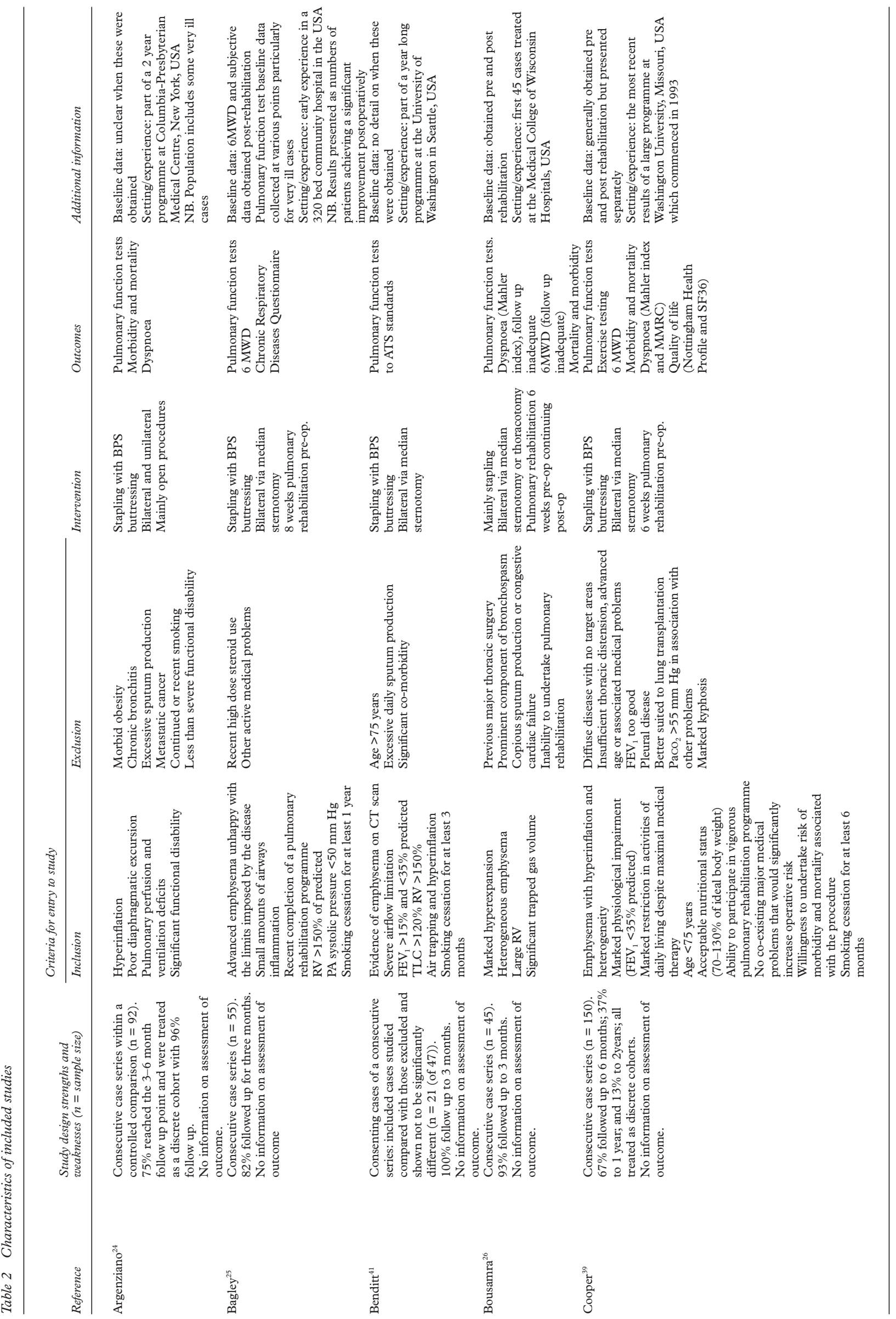




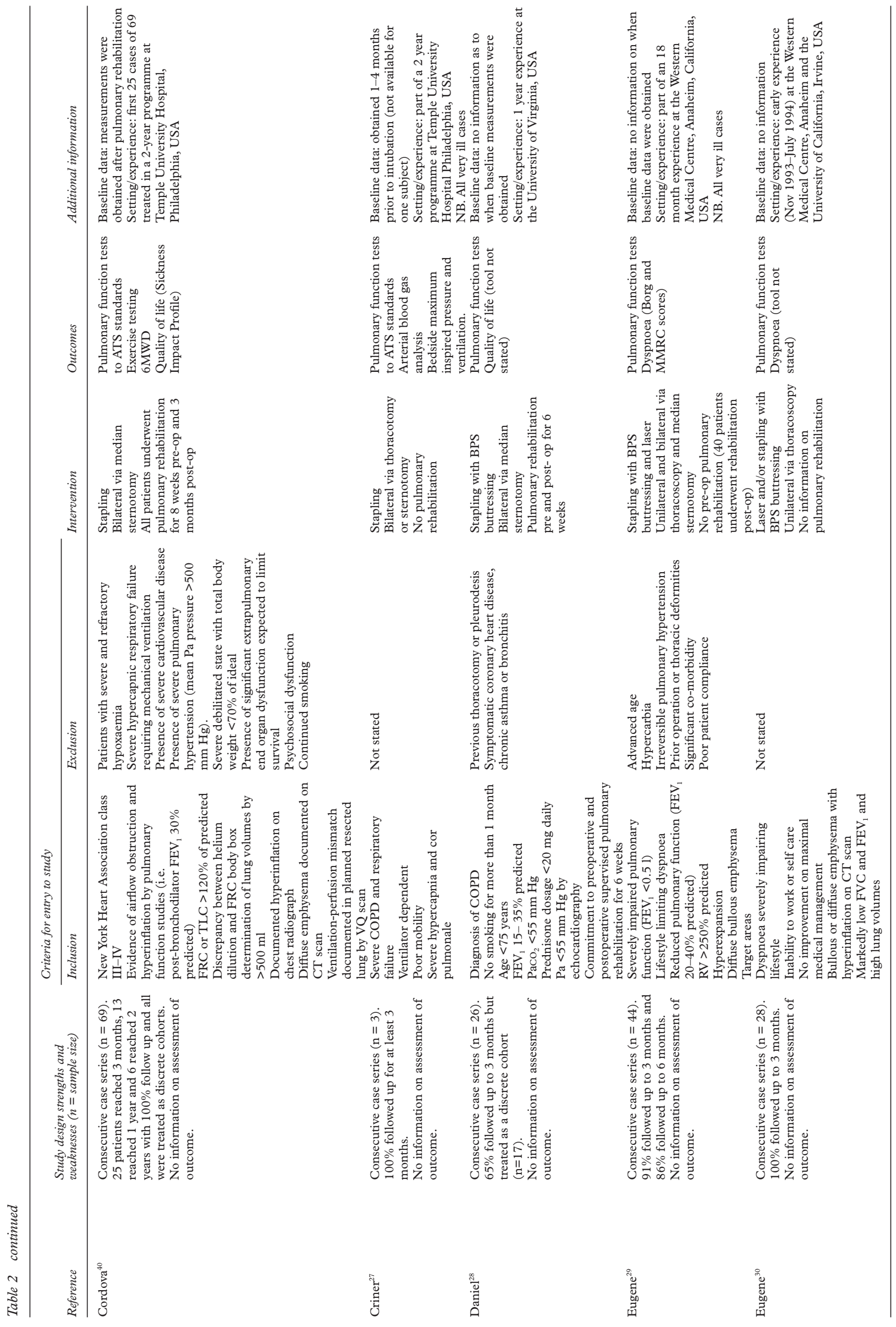




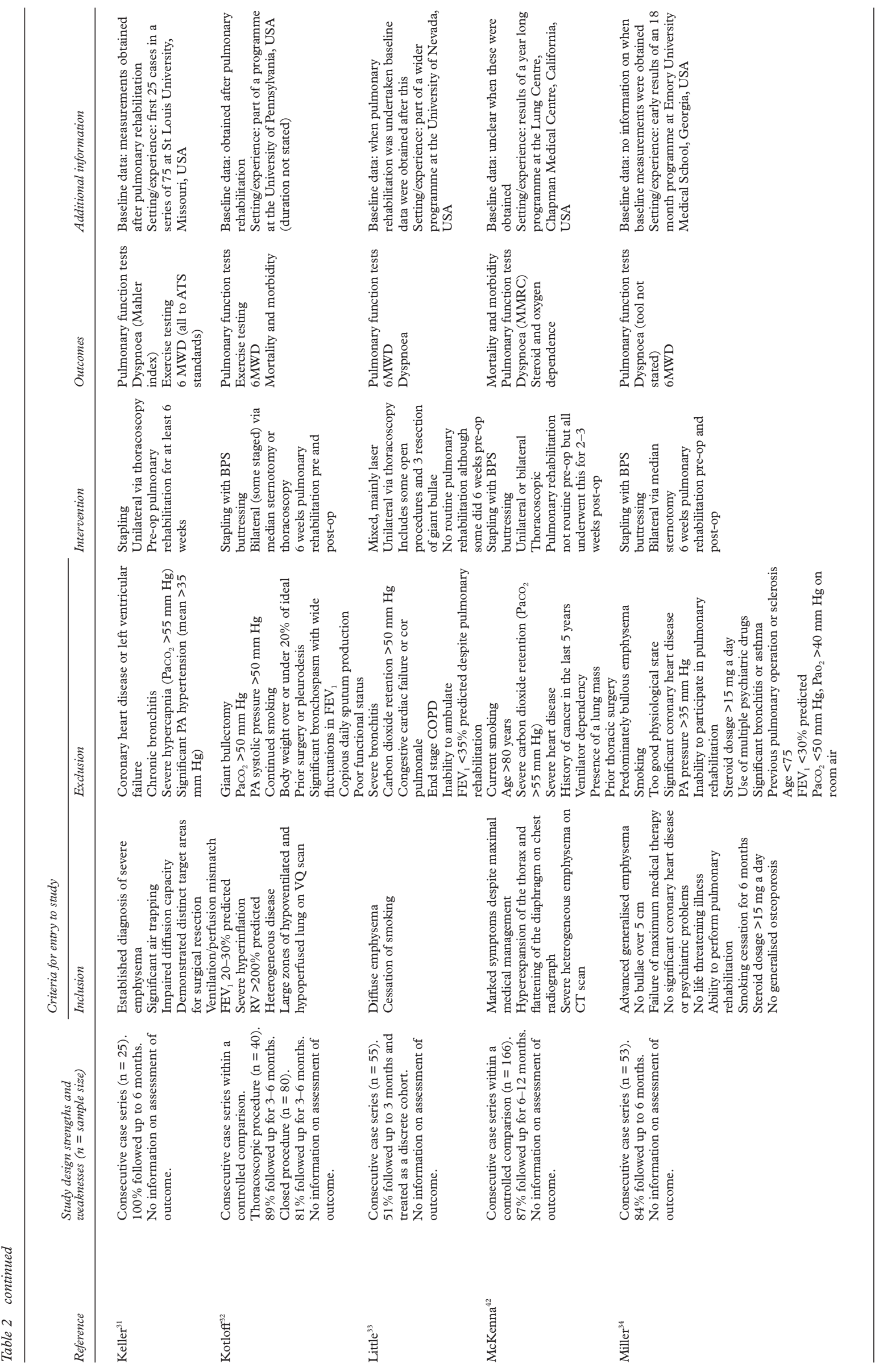




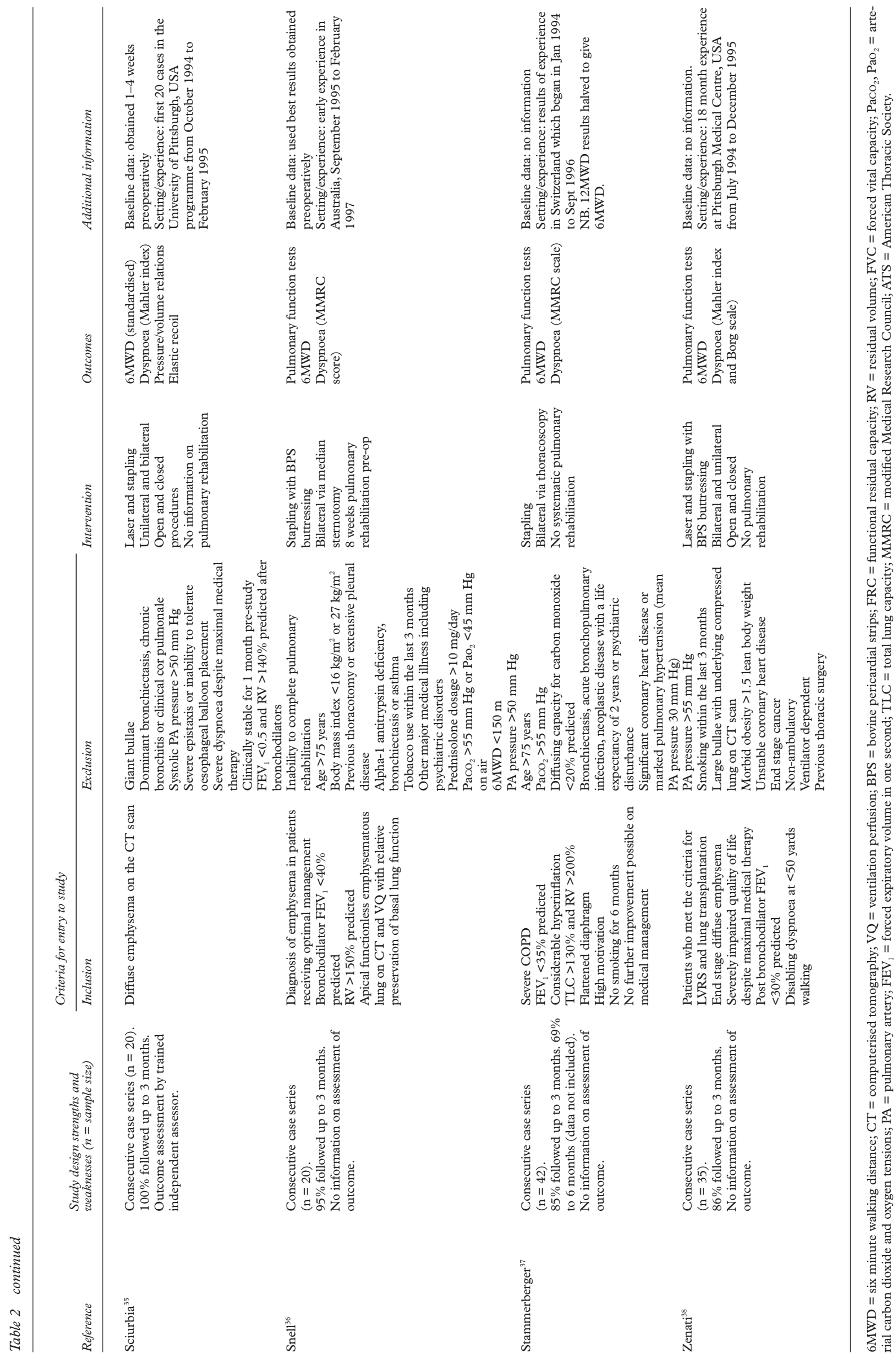


Table 3 Mortality data from included studies

\begin{tabular}{|c|c|c|c|}
\hline Reference (3-6 month follow up) & $\begin{array}{l}\text { Early deaths }(<30 \\
\text { days or hospital } \\
\text { deaths) }\end{array}$ & $\begin{array}{l}\text { Late deaths }(\geqslant 30 \\
\text { days or home } \\
\text { deaths) }\end{array}$ & Overall deaths \\
\hline Argenziano $^{24}$ & $6 / 92(6 \%)$ & $8 / 86(9 \%)$ & $14 / 92(15 \%)$ \\
\hline Bagley $^{25}$ & $3 / 55(5 \%)$ & $3 / 52(6 \%)$ & $6 / 55(11 \%)$ \\
\hline Bousamra $^{26}$ & $3 / 45(7 \%)$ & $2 / 42(5 \%)$ & $5 / 45(9 \%)$ \\
\hline Criner $^{27}$ & $0 / 3(0 \%)$ & $0 / 3(0 \%)$ & $0 / 3(0 \%)$ \\
\hline Daniel $^{28}$ & $1 / 17(6 \%)$ & $0 / 16(0 \%)$ & $1 / 17(6 \%)$ \\
\hline Eugene $^{29}$ & $1 / 44(2 \%)$ & $11 / 43(25 \%)$ & $12 / 44(27 \%)$ \\
\hline Eugene $^{30}$ & $0 / 28(0 \%)$ & $3 / 28(11 \%)$ & $3 / 28(11 \%)$ \\
\hline Keller $^{31}$ & $0 / 25(0 \%)$ & $0 / 25(0 \%)$ & $0 / 25(0 \%)$ \\
\hline Kotloff $(\mathrm{MS})^{32}$ & $5 / 80(6 \%)$ & $6 / 75(8 \%)$ & $11 / 80(14 \%)$ \\
\hline Kotloff (VATS) ${ }^{32}$ & $1 / 40(2 \%)$ & $0 / 40(0 \%)$ & $1 / 40(2 \%)$ \\
\hline Little $^{33}$ & N/A & N/A & $3 / 55(5 \%)$ \\
\hline Miller $^{34}$ & $3 / 53(6 \%)$ & $2 / 50(4 \%)$ & $5 / 53(9 \%)$ \\
\hline Sciurbia $^{35}$ & $0 / 20(0 \%)$ & $0 / 20(0 \%)$ & $0 / 20(0 \%)$ \\
\hline Snell ${ }^{36}$ & $1 / 20(5 \%)$ & $0 / 20(0 \%)$ & $1 / 20(5 \%)$ \\
\hline Stammberger ${ }^{37}$ & $0 / 42(0 \%)$ & $3 / 42(7 \%)$ & $3 / 42(7 \%)$ \\
\hline Zenati $^{38}$ & $0 / 35(0 \%)$ & $0 / 35(0 \%)$ & $0 / 35(0 \%)$ \\
\hline IQ range & $0-6 \%$ & $0-8 \%$ & $0-11 \%$ \\
\hline \multicolumn{4}{|l|}{2 year follow up } \\
\hline Cooper $^{39}$ & $6 / 150(4 \%)^{\star}$ & $4 / 144(3 \%)^{\star}$ & $10 / 150(7 \%)$ \\
\hline Cordova $^{40}$ & $0 / 25(0 \%)$ & $0 / 25(0 \%)$ & $0 / 25(0 \%)$ \\
\hline
\end{tabular}

$\star$ Deaths measured up to and after 90 days.

VATS $=$ video assisted thoracic surgery MS = median sternotomy

$\mathrm{FEV}_{1}$ data were available for 925 patients. At baseline the $\mathrm{FEV}_{1}$ was $0.64-0.731$ (IQR) which rose to 0.91-1.07 1 3-6 months after LVRS with a pre/post difference of $0.23-0.361$. Two studies presented data at two years follow up; Cooper $e t a l^{39}$ found a post-treatment $\mathrm{FEV}_{1}$ of 1.251 and a pre/post test difference of 0.421 , and Cordova et $a l^{40}$ reported a post-treatment $\mathrm{FEV}_{1}$ of 0.911 and a pre/post test difference of 0.221 .

$\mathrm{FEV}_{1}$ as a percentage of the predicted value was presented for 806 patients. Baseline measurements were $24-28 \%$ (IQR). In the short term these rose to $35-41 \%$ and the pre/post test difference was 9-13\%. Only Cooper et a ${ }^{39}$ measured this in the longer term and reported post-treatment results of $36 \%$ and $42 \%$, with pre/post test differences of $12 \%$ and $15 \%$ at one and two years, respectively.

Six minute walking distance (6MWD)

The results of 486 patients for the $6 \mathrm{MWD}$ are presented in table 4 . Ten studies collected data on this outcome. The unit of measurement varied across studies so, to facilitate comparison, all results were converted to metres. The baseline distance covered by study participants was $241-290 \mathrm{~m}$ (IQR). This rose to 306$434 \mathrm{~m}$ after treatment with a pre/post test difference of $32-96 \mathrm{~m}$. Only Cooper et $a l^{39}$ recorded these data in the longer term with differences of $64 \mathrm{~m}$ and $80 \mathrm{~m}$ at one and two years, respectively.

Quality of life

Only four series collected quality of life (QOL) data before and after the procedure (187 patients) and only three of these used specific measurement tools.

Bagley et $a l^{25}$ used the Chronic Respiratory Disease Questionnaire (CRQ) developed by Guyatt and colleagues, ${ }^{43}$ Cooper et $a^{39}$ used two well validated generic quality of life measures (the Nottingham Health Profile ${ }^{44}$ and the SF $36^{45}$ ), and Cordova et al used the Sickness Impact Profile. ${ }^{46}$ Full details of the QOL results are presented in table 5. Although only limited data were presented in the studies, improvements in quality of life were observed across all studies and measurement tools.

\section{Dyspnoea}

Twelve studies measured dyspnoea before and after the intervention. A variety of measurement tools were used but only nine studies

Table 4 Short and long term results of all included studies for forced expiratory volume in one second (FEV, $)$, FEV $V_{1}$ as a percentage of predicted, and six minute walking distance ( $6 M W D)$ in metres

\begin{tabular}{|c|c|c|c|c|c|c|c|c|c|}
\hline \multirow[b]{2}{*}{ Study (n) } & \multicolumn{3}{|c|}{ Mean (SD) FEV } & \multicolumn{3}{|c|}{ Mean $(S D) \%$ predicted $F E V_{1}$} & \multicolumn{3}{|c|}{ Mean (SD) $6 M W D$} \\
\hline & Pre & Post & $\begin{array}{l}\text { Difference } \\
\text { ( } p \text { value) }\end{array}$ & Pre & Post & $\begin{array}{l}\text { Difference } \\
\text { ( } p \text { value) }\end{array}$ & Pre & Post & $\begin{array}{l}\text { Difference } \\
\text { ( } p \text { value) }\end{array}$ \\
\hline \multicolumn{10}{|c|}{ Short term follow up 3-6 months (where studies give results for 3 and 6 months the 6 month results only are presented) } \\
\hline Argenziano $^{24}(66)$ & $0.52(0.19)$ & $0.78(0.38)$ & $0.26 \ddagger$ & $22(8)$ & $34(14)$ & $12 \ddagger$ & $176(96)$ & $273(96)$ & $96 \ddagger$ \\
\hline Bagley $^{25}(55)^{\star}$ & N/A & N/A & $0.19(0.0002)$ & $\mathrm{N} / \mathrm{A}$ & N/A & N/A & $\mathrm{N} / \mathrm{A}$ & N/A & $32(0.042)$ \\
\hline Benditt $^{41}(21)$ & $1.12 \ddagger$ & $1.12 \ddagger$ & $0.00 \ddagger$ & $24 \ddagger$ & $28 \ddagger$ & $4 \ddagger$ & N/A & N/A & N/A \\
\hline Bousamra $^{26}(45)^{\star}$ & $0.68(0.23)$ & $0.97(0.38)$ & $0.29(0.005)$ & $26(9)$ & $40(15)$ & $14(0.002)$ & N/A & N/A & N/A \\
\hline $\operatorname{Cooper}^{39}(101)^{\star}$ & $0.70 \ddagger$ & $1.06 \ddagger$ & $0.36(<0.001)$ & $25 \ddagger$ & $38 \ddagger$ & $13 \ddagger$ & $338 \ddagger$ & $402 \ddagger$ & $64(<0.001)$ \\
\hline Cordova $^{40}(25)^{\star}$ & $0.68(0.19)$ & $0.93^{\top}(0.29)$ & $0.25(<0.001)$ & $27(8)$ & $37^{\top}(12)$ & $10 \ddagger$ & $257^{\top}(113)$ & $338(80)$ & $80(0.001)$ \\
\hline $\operatorname{Criner}^{27}(2)$ & $0.41(0.00)$ & $0.90(0.36)$ & $0.49 \ddagger$ & $38(1)$ & $38(2.80)$ & $0 \ddagger$ & N/A & $\mathrm{N} / \mathrm{A}$ & N/A \\
\hline Daniel $^{28}(17)$ & $0.73 \ddagger$ & $1.02 \ddagger$ & $0.29(<0.0001)$ & $25 \ddagger$ & $36 \ddagger$ & $11 \ddagger$ & N/A & $\mathrm{N} / \mathrm{A}$ & N/A \\
\hline Eugene $^{29}(44)$ & $0.41(0.01)$ & $0.62(0.03)$ & $0.21 \ddagger$ & $15 \ddagger$ & $23 \ddagger$ & $8 \ddagger$ & $\mathrm{N} / \mathrm{A}$ & $\mathrm{N} / \mathrm{A}$ & $\mathrm{N} / \mathrm{A}$ \\
\hline Eugene $^{30}(25)$ & $0.68(0.05)$ & $0.91(0.35)$ & $0.23(<0.001)$ & N/A & N/A & $\mathrm{N} / \mathrm{A}$ & $\mathrm{N} / \mathrm{A}$ & $\mathrm{N} / \mathrm{A}$ & N/A \\
\hline $\operatorname{Keller}^{31}(25)^{\star}$ & $0.80(0.33)$ & $1.05(0.41)$ & $0.25(<0.001)$ & $33(8.40)$ & $35(7.90)$ & $2 \ddagger$ & $289(96)$ & $322(64)$ & $32(0.01)$ \\
\hline Kotloff $(M S)^{32}(80)$ & $0.73(0.24)$ & $1.02(0.40)$ & $0.29 \ddagger$ & $27 \ddagger$ & $38 \ddagger$ & $11 \neq$ & N/A & N/A & N/A \\
\hline Kotloff (VATS) ${ }^{32}(40)$ & $0.73(0.24)$ & $1.00(0.37)$ & $0.27 \ddagger$ & $25 \ddagger$ & $36 \ddagger$ & $11 \ddagger$ & N/A & $\mathrm{N} / \mathrm{A}$ & N/A \\
\hline Little $^{33}(28)^{\star}$ & $0.74(0.07)$ & $0.85(0.06)$ & $0.11(0.009)$ & N/A & N/A & N/A & N/A & N/A & N/A \\
\hline McKenna $^{42}(166)$ & $0.68 \ddagger$ & $0.94 \ddagger$ & $0.26(<0.0001)$ & $26 \ddagger$ & $36 \ddagger$ & $10(<0.0001)$ & N/A & N/A & N/A \\
\hline Miller $^{34}(53)$ & $0.56 \ddagger$ & $1.10 \ddagger$ & $0.54 \ddagger$ & $24 \ddagger$ & $52 \ddagger$ & $28 \ddagger$ & $241 \neq$ & $482 \ddagger$ & $241 \ddagger$ \\
\hline Sciurbia $^{35}(20)$ & $0.87(0.36)$ & $1.11(0.45)$ & $0.24(<0.001)$ & $32(11)$ & $41(14)$ & $9 \ddagger$ & $241(80)$ & $273(80)$ & $32(0.05)$ \\
\hline Snell $^{36}(20)^{\star}$ & $0.72(0.19)$ & $1.07(0.30)$ & $0.35(<0.001)$ & $28(6)$ & $42(11)$ & $14(<0.001)$ & $306(129)$ & $434(129)$ & $129(<0.001)$ \\
\hline Stammberger $^{37}(42)$ & $0.80(0.24)$ & $1.18(0.44)$ & $0.38(<0.001)$ & $29(7)$ & $41(13)$ & $12 \ddagger$ & $241(96) \dagger$ & $338(96) \dagger$ & $96(0.001) \dagger$ \\
\hline Zenati $^{38}(35)$ & $0.64(0.22)$ & $0.97(0.38)$ & $0.33(<0.0001)$ & $22 \ddagger$ & $35 \ddagger$ & $13 \ddagger$ & $273(80)$ & $306(64)$ & $32(<0.05)$ \\
\hline IQ range & $0.64-0.74$ & $0.91-1.07$ & $0.23-0.36$ & $24-28$ & $35-40$ & $9-13$ & $241-290$ & $306-434$ & $32-96$ \\
\hline \multicolumn{10}{|c|}{ Long term 1 year follow up } \\
\hline Cooper $^{39}(56)^{\star}$ & $0.69 \ddagger$ & $1.00 \ddagger$ & $0.31 \ddagger$ & 24 & 36 & $12 \ddagger$ & 354 & 418 & $64 \ddagger$ \\
\hline $\operatorname{Cordova}^{40}(13)^{\star}$ & $0.66(0.17)$ & $0.90(0.35)$ & $0.22(<0.05)$ & $\mathrm{N} / \mathrm{A}$ & $\mathrm{N} / \mathrm{A}$ & N/A & $\mathrm{N} / \mathrm{A}$ & $\mathrm{N} / \mathrm{A}$ & N/A \\
\hline \multicolumn{10}{|c|}{18 months to 2 years follow up } \\
\hline Cooper $^{39}(20)^{\star}$ & $0.83 \ddagger$ & $125 \ddagger$ & $0.42 \ddagger$ & 27 & 42 & $15 \ddagger$ & 370 & 450 & $80 \ddagger$ \\
\hline $\operatorname{Cordova}^{40}(6)^{\star}$ & $0.69(0.20)$ & $0.91(0.37)$ & $0.22^{\top}(<0.12)$ & $\mathrm{N} / \mathrm{A}$ & N/A & N/A & N/A & N/A & N/A \\
\hline
\end{tabular}

VATS = video assisted thoracoscopy; $\mathrm{MS}=$ median sternotomy; $\mathrm{N} / \mathrm{A}=$ data not available.

* Baseline data appear to have been obtained after pulmonary rehabilitation in the majority of patients.

$\dagger 12 \mathrm{MWD}$ halved.

$\ddagger$ Standard deviations/p value not given. 
Table 5 Results of quality of life data for included studies

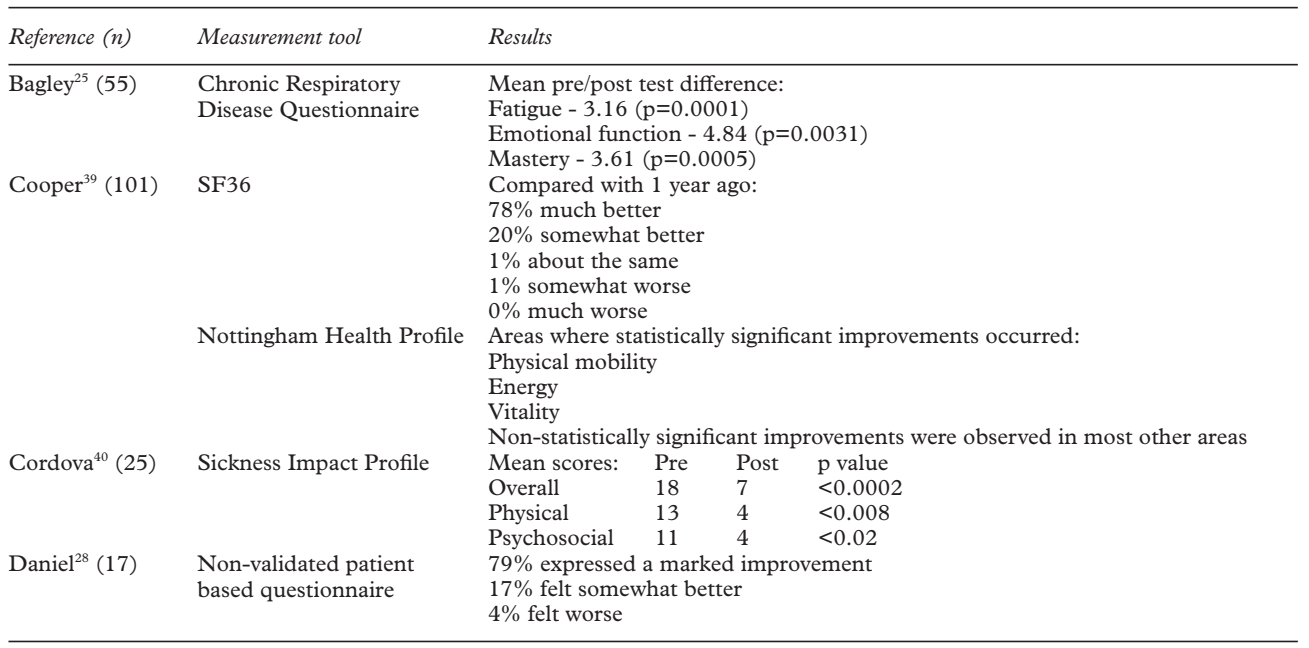

used validated standardised tools. The most commonly used tool was the modified (American Thoracic Society) Medical Research Council of Great Britain scale (MMRC). ${ }^{47}$ The MMRC scale results for 403 patients are presented in table 6.

Bagley et $a l^{25}$ used the $\mathrm{CRQ}^{43}$ and recorded a mean improvement of $5.84(\mathrm{p}=0.0001)$. The Borg scale was used in two studies. ${ }^{48}$ In the series reported by Eugene et $a l^{29}$ the mean score decreased from 7.6 before surgery to 4.65 postoperatively, and Zenati et $a l^{88}$ reported a decrease from 3.71 to 2.4. (The extreme difference in baseline is accounted for by the fact that the patients in the study of Eugene et a ${ }^{29}$ were all very ill.) The Mahler baseline dyspnoea index (BDI) and transitional dyspnoea index (TDI) were used by a number of studies. ${ }^{49}$ Three studies reported scores for the functional impairment component individually ${ }^{31} 38$ with BDI scores of $0.83,0.9$, and 1.0, respectively, and TDI scores of $2.2,1.65$, and 1.72. Keller et $a{ }^{\beta 1}$ reported an overall baseline focal score (BFS) of 3.36 and a transitional focal score (TFS) of 6.12 , and Sciurbia et $a^{\beta^{5}}$ an overall TFS of 5.1 $(\mathrm{p}<0.001)$.

Length of hospital stay

Several series (668 patients) also provided information on length of stay in hospital which gives a crude indication as to resource use associated with the procedure. In those studies which reported it the IQR for length of hospital stay was $13-18$ days.

Supplemental oxygen

Several studies (487 patients) also provided data on supplemental oxygen use before and after the procedure. This provides a crude

Table 6 Individual study results for the MMRC dyspnoea scale

\begin{tabular}{llll}
\hline Study $(n)$ & $\begin{array}{l}\text { Mean }(S D) \text { pre-test } \\
\text { score }\end{array}$ & $\begin{array}{l}\text { Mean }(S D) \text { post-test } \\
\text { score }\end{array}$ & Mean difference \\
\hline Argenziano $^{24}(66)$ & $4.1(0.8)$ & $1.7(1.3)$ & -2.4 \\
$\operatorname{Cooper}^{39}(101)$ & 2.8 & 1.2 & -1.6 \\
$\operatorname{Eugene}^{29}(44)$ & 3.9 & 2.35 & $-1.55(\mathrm{p}<0.01)$ \\
$\operatorname{McKenna}^{42}(166)$ & 2.9 & 1.9 & $-1.0(\mathrm{p}<0.0001)$ \\
Snell $^{16}(20)$ & $3.4(0.5)$ & $2.1(0.8)$ & $-1.3(\mathrm{p}<0.001)$ \\
Stammberger $^{37}(42)$ & $3.5(0.7)$ & $1.6(1.0)$ & -1.9 \\
\hline
\end{tabular}

indication of resource use, quality of life, and functional ability. In the short term (3-6 months) the reduction in the percentage of patients requiring supplemental oxygen, either continuously or on exertion, was $16-42 \%$ (IQR). Cooper $e t a l^{39}$ reported a reduction of $41 \%$ at one year and $52 \%$ at two years.

SUMMARY OF RESULTS

The main effects of LVRS observed in unselected case series with complete follow up are outlined below:

- the pattern of results for most outcomes is fairly consistent across individual studies despite a significant degree of clinical heterogeneity;

- significant short term benefits occurred across a range of outcomes which appear to continue in the longer term;

- physiological improvements in $\mathrm{FEV}_{1}$ appear to be matched by functional improvements in 6MWD and subjective improvements in dyspnoea and quality of life, although information on the latter is only available for small numbers of patients;

- operative mortality rates are low and overall mortality rates compare favourably with those of the COPD population as a whole.

\section{Discussion}

At face value there appears to be a wealth of evidence supporting the effectiveness of LVRS. However, the review also reveals that the most rigorous available relevant research studies employ designs that make them susceptible to bias. This fact, and whether the methods of the review itself might have introduced further bias, needs to be considered before drawing final conclusions.

The systematic approach to the reviewing process which involved a clear definition of the question to be addressed; the development of a protocol; a comprehensive search strategy; clearly defined inclusion and exclusion criteria; and a detailed assessment of the quality of included studies should have minimised any bias introduced in the process of summarising the most rigorous available research literature. 


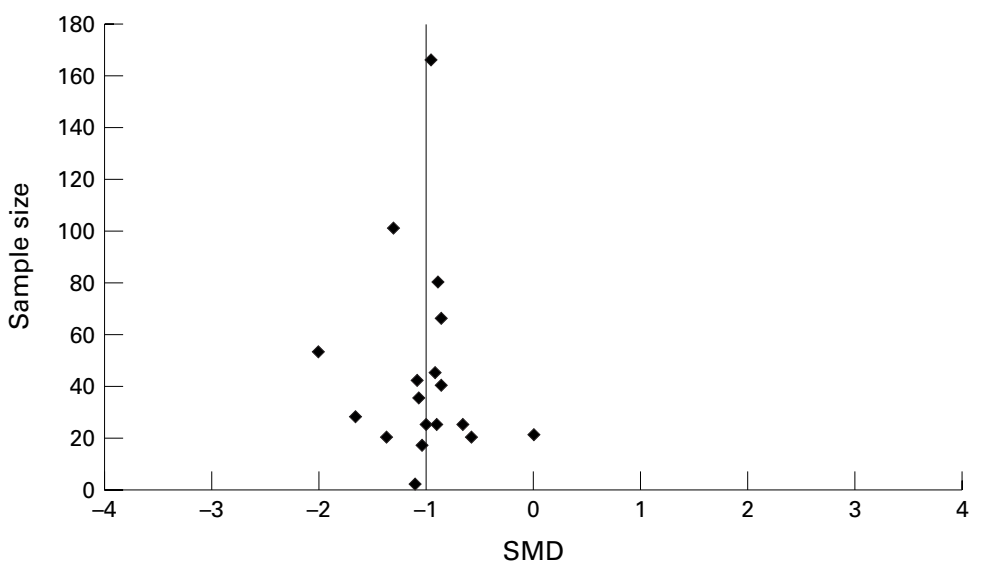

Figure 1 Funnel plot of $18^{\star}$ standardised mean differences (SMD) for forced expiratory volume in one second (FEV) by sample size. ${ }^{\star}$ Excludes one extreme outlier ${ }^{29}$ which extended the $x$ axis and hampered interpretation of the plot.

Despite this, freedom from bias cannot be guaranteed. We would suggest that the greatest possible threat is from publication bias, particularly as knowledge on the impact of this is least well explored where studies other than randomised controlled trials are being reviewed. The funnel plot in fig 1 which plots sample size against the standardised mean difference for $\mathrm{FEV}_{1}$ in the included studies acts as a crude visual check on the likelihood of missing studies. ${ }^{50}$ It indicates that for this outcome there are no large gaps in the data set which might be suggestive of publication bias.

The main sources of bias in the included studies relate to their lack of parallel control groups. ${ }^{51}$ Where outcome measurements can be made before and after an intervention, as is the case for $\mathrm{FEV}_{1}, 6 \mathrm{MWD}$, dyspnoea score, and quality of life, the problems of interpretation are reduced but not eliminated for two reasons.

Firstly, the attribution of all or any observed change to LVRS is uncertain. Many factors other than LVRS may have influenced the difference between the pre- and post-treatment outcome measurements. Particularly important in this sense is the role of pulmonary rehabilitation. All LVRS "packages" in the included studies incorporated a component of postoperative rehabilitation and, although it was often unclear whether the pre-treatment measures were made before or after any preoperative pulmonary rehabilitation, it seems likely that in many studies the LVRS "package" would have included preoperative pulmonary rehabilitation too. Without a parallel control group it is impossible to exclude the possibility that pulmonary rehabilitation alone might have been responsible for a considerable component of the improvement in critical outcomes such as $6 \mathrm{MWD}$, dyspnoea, and quality of life. ${ }^{23}$

Secondly, the included studies are open to detection bias. With only one study arm it is inevitable that clinicians and patients are aware that they are on an active treatment and may tend to provide outcome measurements which conform to expectations that LVRS will result in improvement. The use of validated and standardised outcome collection methods offers some protection against this. Making the assessment of outcome independent of knowledge that a patient was part of a study testing the effectiveness of LVRS would provide further protection, but we have confirmed that this was not applied in any of the included studies.

Where outcome measurements before and after the intervention are not applicable, as in the case of mortality, the absence of a parallel control group poses much greater problems. Any comparison must rely on measurement of that outcome in an untreated group outside the study. This group may have important differences in characteristics other than treatment which could in turn account for any differences in observed outcome.

It is possible to judge that the biases identified above, and others not specifically mentioned, may not substantively alter the assessment of whether the observed impact on outcomes truly reflects the actual impact. We believe, however, that it is highly likely that they will and, further, that observed improvements in outcome will tend to be overestimates. More conservatively, it seems clear that the identified biases introduce uncertainty which widens the true range of possible size of effects on mortality, $\mathrm{FEV}_{1}, 6 \mathrm{MWD}$, dyspnoea score, and quality of life well beyond the IQ ranges demonstrated by the review. This uncertainty is intensified when attempts are made to summate the value of the individual effects of LVRS into an assessment of overall effectiveness, and compounded further by the fact that the two effects likely to be valued most highly in assessing overall effectiveness-impact on mortality and quality of life - are those where uncertainty is greatest either because of the biases discussed or the limited number of included studies collecting data on the outcome.

However, this should not obscure the fact that LVRS, with or without pulmonary rehabilitation, has led to subjective improvements in quality of life and shortness of breath. This is consistently shown in the small number of studies that examined them. The impact on these outcomes is supported by improvements in more objectively measured physiological and functional measures such as $\mathrm{FEV}_{1}$ and 6MWD. Improvements in these measures are also consistent across a much larger number of studies. Finally, mortality rates associated with the operation are also consistent across individual studies and compare favourably with those of untreated patients with COPD who have high mortality rates even on maximum medical management. $^{52}$

Based on the results of the studies included in this review the authors judge that the benefits of LVRS are likely to outweigh the risks. It seems unlikely that the biases inherent in the design of the included studies would have so exaggerated effect sizes that the research reviewed conveys overall effectiveness where it is actually completely ineffective. However, it is possible that the observed results from the most rigorous existing research, taking into account the likely biases, could actually be compatible with a true level of net benefit from LVRS which does not justify its 
costs. Thus, although this systematic review supports LVRS as a promising option in the management of patients with severe end stage emphysema, it also explains current uncertainty and supports the view that further rigorous research, particularly randomised controlled trials, are required to resolve this. One such trial is currently in progress in the UK which will incorporate an economic evaluation, ${ }^{53}$ and another is ongoing in the USA. ${ }^{54}$ Until the results of these are available, debate will continue on whether LVRS has a secure place among routinely available treatments for end stage COPD secondary to severe emphysema.

The authors wish to express their thanks to Lisa Gold (Health Economics Facility, Birmingham) and Mr B Rajesh (West MidEconomics Facility, Birmingham) and Mr B Rajesh (West Mid-
lands Regional Thoracic Surgery Unit, Birmingham) for their advice and support.

1 Geddes DM. Airways obstruction. Topics in Respiratory Disease Series. Aancaster: MTP Press, 1981.

2 Detels R, Holland W, McEwen J, et al, eds. Oxford textbook of public health. Volume 3. The practice of public health. 3rd ed. Oxford: Oxford University Press, 1997: 1019-651.

3 Anderson HR, Esmail A, Hollowell J, et al. Lower respiratory disease. In: Stevens A, Raftery J, eds. Health care needs assessment. Volume 1. Oxford: Radcliffe Medical Press, 1994: 256-340.

4 COPD Guidelines Group of the Standards of Care Committee of the British Thoracic Society. BTS guidelines for the management of chronic obstructive pulmonary disease. Thorax 1997;52(Suppl 5):S1-28.

5 Brantigan OC, Mueller E. Surgical treatment of pulmonary emphysema. Am Surg 1957;23:789-804.

6 Brantigan OC, Mueller E, Kress MB. A surgical approach to pulmonary emphysema. Am Rev Respir Dis 1959;80:194202.

7 Cooper JD, Trulock EP, Triantafillou AN, et al. Bilateral pneumectomy (volume reduction) for chronic obstructive pneumectomy (volume reduction) for chronic obstructive
pulmonary disease. $\mathcal{F}$ Thorac Cardiovasc Surg 1995;109: pulmonary

8 Cooper JD. Technique to reduce air leaks after resection of emphysematous lung. Ann Thorac Surg 1994;57:1038-9.

9 Brenner M, Yusen R, McKenna R, et al. Lung volume reduction surgery for emphysema. Chest 1996;110:205-18.

10 Lomas DA, Caine N, Wells FC. Health technology assessment: time for a randomised controlled trial of the role of lung volume reduction surgery in the treatment of emphysema. Thorax 1997;52:755-6.

11 Kwankam M. Lung volume reduction surgery (LVRS). Ottowa: Alberta Heritage Foundation for Medical Research, 1998: 1-12.

12 Cooper J. The history of surgical procedures for emphysema. Ann Thorac Surg 1997;63:312-9.

13 Janssen W. Treatment for emphysema: an overview of lung volume reduction surgery. Perspect Respir Nurs 1996;7:1-5

14 Snider G. Health-care technology assessment of surgical procedures. The case of reduction pneumoplasty for

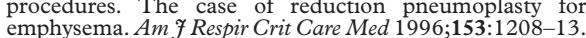

15 Snider G. Reduction pneumoplasty for giant bullous emphysema. Implications for surgical treatment of nonbulemphysema. Implications for surgical trea

16 Holohan TV, Handelsman H. Lung volume reduction surgery for end-stage chronic obstructive pulmonary disease. Health Technology Assessment Series AHCPR Publication No. 96-0062. Rockville, Maryland: Agency for Health Care Policy and Research, 1996.

17 Sciurbia F. Early and long-term functional outcomes following lung volume reduction surgery. Clin Chest Surg Med 1997;18:259-76.

18 Tonelli MR, Benditt JO, Albert RK. Clinical experimentation. Lessons from lung volume reduction surgery. Chest 1996;110:230-8.

19 Russi EW. Physiological outcomes of lung volume reduction surgery. Monaldi Arch Chest Dis 1997;52:155-8.

20 Lavell DR, Higgins VR. Lung surgery. When less is more. Registered Nurse 1995; July:40-5.

21 Davies L, Calverley P. Lung volume reduction surgery in chronic obstructive pulmonary disease. Thorax 1996; 51(Suppl 2):S29-34.

22 Naunheim K, Ferguson M. The current status of lung volume reduction operations for emphysema. Ann Thorac volume reduction operat

23 Lacasse Y, Wong E, Guyatt GH, et al. Meta-analysis of respiratory rehabilitation in chronic obstructive pulmonary disease. Lancet 1996;348:1115-9.

24 Argenziano M, Thomashow B, Jellen PA, et al. Functional comparison of unilateral versus bilateral lung volume reduction surgery. Ann Thorac Surg 1997;64:321-7.

25 Bagley PH, Davis SM, O'Shea M, et al. Lung volume reduction surgery at a community hospital: program development and outcomes. Chest 1997;111:1552-9.
26 Bousamra M, Haasler GB, Lipchik RJ, et al. Functional and oximetric assessment of patients after lung reduction surgery. F Thorac Cardiovasc Surg 1997;113:675-81.

27 Criner GJ, O'Brien G, Furukawa S, et al. Lung volume reduction surgery in ventilator dependent COPD patients. Chest 1996;110:877-84.

28 Daniel TM, Chan BB, Bhaskar V, et al. Lung volume reduction surgery. Case selection, operative technique and clinical results. Ann Thorac Surg 1996;223:526-31.

29 Eugene J, Dajee A, Kayaleh R, et al. Reduction pneumoplasty for patients with a forced expiratory volume in one second of 500 millilitres or less. Ann Thorac Surg 1997;63: $186-92$.

30 Eugene J, Ott RA, Gogia HS, et al. Video-thoracic surgery for treatment of end-stage bullous emphysema and chronic obstructive pulmonary disease. Am Surg 1995;61:934-6.

31 Keller CA, Ruppel G, Hibbett A, et al. Thoracoscopic lung volume reduction surgery reduces dyspnoea and improves exercise capacity in patients with emphysema. Am $\mathcal{F}$ Respir Crit Care Med 1997;156:60-7.

32 Kotloff RM, Tino G, Bavaria JE, et al. Bilateral lung volume reduction surgery for advanced emphysema: a comparison of median sternotomy and thoracoscopic approaches. Chest 1996;110:1399-406

33 Little AG, Swain JA, Nino JJ, et al. Reduction pneumoplasty for emphysema. Ann Surg 1995;222:365-74.

34 Miller JI, Lee RB, Mansour KA. Lung volume reduction surgery: lessons learned. Ann Thorac Surg 1996;61:1464-9.

35 Sciurbia FC, Rogers RM, Keenan RJ, et al. Improvement in pulmonary function and elastic recoil after lung volume reduction surgery for diffuse emphysema. $N \mathrm{Engl} 7 \mathrm{Med}$ 1996;334:1095-9

36 Snell GI, Solin P, Weng Chin, et al. Lung volume reduction surgery for emphysema. Med F Aust 1997;167:529-32.

37 Stammberger U, Thurnheer R, Bloch KE, et al. Thoracoscopic bilateral lung volume reduction surgery for diffuse pulmonary emphysema. Eur f Cardiothorac Surg 1997;11 1005-10.

38 Zenati M, Keenan RJ, Sciurbia FC, et al. Role of lung volume reduction surgery in lung transplant candidates with pulmonary emphysema. Ann Thorac Surg 1996;62: 994-9.

39 Cooper JD, Patterson GA, Sunderesan RS, et al. Results of 150 consecutive bilateral lung volume reduction procedures in patients with severe emphysema. Thorac Cardiovasc Surg 1996;112:1319-29.

40 Cordova F, O'Brien G, Furukawa S, et al. Stability of improvements in exercise performance and quality of life following bilateral lung volume reduction surgery in severe COPD. Chest 1997;112:907-15.

41 Benditt JO, Lewis S, Wood DE, et al. Lung volume reduction surgery improves maximal $\mathrm{O}_{2}$ consumption, maximal minute ventilation, $\mathrm{O}_{2}$ pulse and dead space to tidal volume ratio during leg cycle ergometry. Am f Respir Crit Care Med 1997;156:561-6.

42 McKenna RJ, Brenner M, Fischel RJ, et al. Should lung volume reduction surgery be unilateral or bilateral? 7 Thorac Cardiovasc Surg 1996;112:1331-9.

43 Guyatt GH, Berman LB, Townsend M, et al. A measure of quality of life for clinical trials in chronic lung disease. Tho$\operatorname{rax} 1987 ; 42: 773-8$.

44 Hunt S, McKenna S, McEvew J, et al. The Nottingham Health Profile: subjective status and medical consultations. Soc Sci Med 1981;15A:221-9.

45 Ware J, Sherbourne C. The MOS 36-item short-form health survey (SF-36). Conceptual framework and item selection. Med Care 1992;30:473-81.

46 Bergner M, Bobbitt RA, Carter WB, et al. The sickness impact profile: development and final revision of a health status measure. Med Care 1981;19:787-805.

47 Sweer L, Zwillich CW. Dyspnoea in the patient with chronic obstructive pulmonary disease. Clin Chest Med 1990;11: 417-45.

48 Borg G. Perceived exertion as an indicator of somatic stress. Scand F Rehabil Med 1970;2:92-8.

49 Mahler DA, Faryniarz K, Tomlinson D, et al. Impact of dyspnoea and physiological function on general health status in patients with chronic obstructive pulmonary disease. in patients with chronic

50 Egger M, Davey Smith G, Schneider M, et al. Bias in metaanalysis detected by a simple, graphical test. BMF 1997;315:629-34.

51 Campbell DT, Stanley JC. Experimental and quasiexperimental designs for research. Chicago: Rand McNally College Publishing Company, 1966.

52 Celli R, Snider GL, Heffner J, et al. American Thoracic Society standards for the diagnosis and care of patients with chronic pulmonary disease. Am $\mathcal{7}$ Respir Crit Care Med 1995;152(Suppl):S77-120.

53 National Research Register. A multi centre randomised controlled trial of lung volume reduction surgery in patients with extensive emphysema (pre-protocol). The National Research Register. NRR Project N0287024092, 1999

54 Utz JP, Hubmayr RD, Deschamps C. Lung volume reduction surgery for emphysema: out on a limb without a NETT. Mayo Clin Proc 1998;73:603. 